\title{
Optimal Portfolio Selection of GenCo Under Congestion Risk in Multimarket Environment
}

\author{
Debasmita Panda $^{1} \cdot$ S. N. Singh ${ }^{1}$
}

Received: 2 January 2017 / Accepted: 7 July 2017 / Published online: 19 July 2017

(C) Springer Nature Singapore Pte Ltd. 2017

\begin{abstract}
In a restructured electricity market derivative instruments help in reducing price risk. This paper proposes a portfolio optimization model considering uncertainty of electricity spot prices. Using this model, a thermal generation company (GenCo) holding contracts within and outside its jurisdiction can maximize its profit with limited risk exposure. The proposed model is formulated using mean variance portfolio theory, considering spot market, bilateral contracts and options with the possibility of managing congestion risk while trading between different locations. To handle uncertainties scenario generation and reduction techniques are used. The spot price inaccuracies are further represented as scenario tree. The producers risk preference is expressed by a utility function as the trade-off between expectation and variance of the return. For multiple scenarios the optimization problem is solved to obtain a stochastic solution to the optimal capacity allocation problem. The work addresses price variability of zonal transaction considering both physical and financial contracts to schedule the output of an opportunistic GenCo for maximizing its profit by creating hedging strategy through multiple scenarios. The results indicate that the proposed model is capable of improving the profit risk trade-off of the portfolios. GenCos profit seeking behavior during congestion relieving situation has also been demonstrated in the proposed
\end{abstract}

Debasmita Panda

psmita@iitk.ac.in; pandadebasmita4@gmail.com

1 Department of Electrical Engineering, Indian Institute of Technology Kanpur, Kanpur, Uttar Pradesh, India risk modeling. Study is performed on a GenCo situated in NORDPOOL market.

Keywords Portfolio optimization - Risk management · Scenario generation $\cdot$ Congestion hedging $\cdot$ Options

$\begin{array}{ll}\text { Abbreviations } \\ \text { BR } & \text { Backward Reduction } \\ \text { CfD } & \text { Contract for Difference } \\ \text { CVaR } & \text { Conditional Value at Risk } \\ \text { EF } & \text { Efficient Frontier } \\ \text { GAMS } & \text { General Algebraic Modeling System } \\ \text { MCP } & \text { Market Clearing Price } \\ \text { MINLP } & \text { Mixed Interger Non-Linear Programming } \\ \text { MO } & \text { Market Operator } \\ \text { NLP } & \text { Non-Linear Programming } \\ \text { SBB } & \text { Standard Branch and Bound } \\ \text { SP } & \text { Sub-Plot } \\ \text { VaR } & \text { Value at Risk }\end{array}$

\section{Introduction}

In a competitive market a GenCo aims to maximize its profit with minimum risk by selling its energy in a variety of available contracts. Various contracts available are, pool market, bilateral contract, derivative products and contracts between zones. Since the electricity market price is uncertain, a GenCo tries to optimally allocate its output while controlling the risk of price volatility. Volatility and competitiveness in energy markets force GenCos to act strategically to maximize profit.Portfolio optimization helps GenCos in 
maximizing their profit through optimal allocation of contracts and hedging of risk [1-3]. Further, price uncertainty across markets affects GenCos trading decision making. Therefore, it is important to consider various effects of market uncertainties in trading strategy.

Reference [4, 5] discusses derivatives such as futures, forwards, swaps and options. Future contracts are of financial nature giving the contract holder the right to exercise it during certain time in future at a fixed price, based on certain amount of money known as option premium [6-9]. Forward contracts are the contract between two parties to buy and sell an asset at a specified future time at an agreed upon price. The contract for difference (CfDs) [10] is the contract between two diverging area prices to manage the risk of locational price spread.

Reference [11] presents a stochastic model for coordination of physical and financial contracts under the price volatility. Portfolio optimization using forward contracts on electricity market and natural gas is discussed in [12]. Development of option contract for electricity market trading is discussed in [13]. A brief life cycle view of a future contract is given in $[14,15]$. The impact of physical and financial contracts on producer's bidding strategies has been studied in [16]. Reference [17] discusses the economics of electricity hedging using future contracts. Reference [18] deals with the design of forward contracts bundled with financial options for electricity risk management. A statistical study of direct and cross hedging using future contracts is given in [9]. Based on mean variance portfolio theory, an analytical approach is proposed in [3] for optimal energy allocation between spot and bilateral contract markets. The authors in [19] proposed a multi-period optimal contract allocation using mean variance theory considering producers risk preferences.

Conejo et al. [20] proposed a conditional value at risk (CVaR) based risk-constraint profit maximization model with forward contract involvement to hedge risk of pool price volatility. A case study highlighting advantages of options to managem financial risks in electricity market is discussed in [21, 22]. A Nash model to find equilibrium pricing of future market and optimal generation asset allocation considering spot price risk is proposed by Guan et al. [23]. Use of asian options with its pricing strategies to improve market equilibrium in day ahead market risk hedging is shown in [24].

Available literature discusses a situation of GenCos intrazonal bidding with an aim to mitigate spot price risks. However inter zonal transaction may lead to congestion risk that arises from difference in locational prices of involved multiple locations. Studies show use of FTR [28] and other congestion management instruments. However these financial instruments risk hedging strategies are not suitable for a short-term market like day-ahead market involving multiple contracts. Therefore the work proposed here uses options as a congestion hedging tool for multizonal markets. This approach is applicable to power producers involving inter regional power transfer.

This paper proposes a mean variance approach $[25,26]$ to investigate short term commercial decisions of a GenCo holding contracts with multiple locations considering congestion effect. The fundamental difference between this approach and others in the available literature is the consideration of multiple zones to demonstrate the concept of hedging congestion charges with options, along with forward and spot contracts. A scenario generation model is proposed to govern the stochastic evolution of spot prices. BR (backward reduction) algorithm is used to reduce the number of scenarios and facilitates the construction of scenario tree. Variance-covariance relation between the expected profit and risk is considered to generate the trade off curve. A case study based on a realistic market is presented.

\section{Hedging Positions}

Multi-zonal markets carry the risk of spot price uncertainty and inter-zonal congestion. GenCo as a profit seeking producer, decides to take congestion hedging position by trading in options. GenCos trading decision to opt for hedging position is not to make profit from it, but to protect itself from inter-zonal spot price (congestion) risks. Hedging can be of direct type or cross type. Direct hedge is risk less hedging positions i.e., the trading participant is fully hedged. A cross hedge is the act of hedging one contract position by taking an offset position in another contract.

Reference [27] shows comparative hedging positions of future contracts in relation to crude oil contracts in a deregulated electricity market. Collin in [17] discussed economics of electricity hedging from risk management. Financial transmission rights (FTR) are important instruments for hedging congestion risks. $\mathrm{Li}$ et al. in [28] proposed a risk constrained FTR bidding strategy in transmission auction markets. A day ahead profit hedging model accounting for imbalances that arises from infeasible dispatch schedule accepted by market operator (MO) is given in [29].

With multiple markets the price differential between areas is volatile and this gives rise to congestion risk. This paper identifies effective involvement of options for crosshedging congestion risks and also calculates the amount of options that minimize the risk. A congestion relieving situation has also been demonstrated. Several approaches are discussed in literature to find the optimal hedging position. This paper uses mean variance model to find the optimal hedge position by maximizing mean return thereby minimizing variance. A higher variance makes it difficult to find optimal revenue meet of a GenCo in electricity market. 


\section{Problem Formulation}

\section{Solution Framework}

The paper aims to determine an optimal power portfolio for a GenCo in multi-market environment. A time period $(T)$ of 1 month is considered with each hour as trading interval. The number of contracts for the entire period of study is decided. These include spot market, forward (bilateral) contract, inter-zonal contract and options as hedging contract. The spot market considered in this paper is a day-ahead market based on a power pool with uniform market clearing price (MCP) mechanism.

\section{Scenario Consideration}

The uncertainties of electricity spot prices are modeled by creating possible set of scenarios based on Monte Carlo simulation method. This essentially approximates the required number of samples with associated probability for a given accuracy level independent of system size. This makes it suitable for large scale simulations. Nevertheless, a large number of scenarios increases the computational burden and also time consuming for solving the stochastic programming problem. Therefore, a mathematical model to reduce such scenarios is essential. A scenario reduction methodology reduces the scenario set while keeping the stochastic information embedded in it.

\section{Scenario Tree Construction}

The proposed scenario reduction technique controls the goodness-of-fit of approximation by measuring the distance between probability distribution as a probability metric. Electricity spot prices at different locations are approximated to form the stochastic vector for scenario consideration. Monthly prices of the past years are taken to define the range (minimum and maximum) for the forecast spot price. Minimum and maximum values of the forecast data are used to create price scenarios for each hour.

Efficient algorithms based on backward reduction method is developed that determine optimal reduced measures. Simultaneous backward reduction and fast forward methods are briefly introduced below [30, 31].

Let $\zeta_{w}(w=1, \ldots, N)$ denotes $N$ scenarios, each with a probability of $p_{w}$. Considering $D T_{w, w^{\prime}}$ as the distance of scenario pair $\left(w, w^{\prime}\right)$, the backward reduction technique follows as,

1- Let $W$ denotes the initial set of scenarios and $D W$ be the scenarios to be deleted. $D W$ is set as null initially. The distance between all scenario pairs is computed as: $D T_{w, w^{\prime}}=D T\left(\zeta_{w}, \zeta_{w^{\prime}}\right) ; w, w^{\prime}=1, \ldots, N$
2- For each scenario $s, D T_{s}(r)=\min D T_{s, w^{\prime}} ; w^{\prime}, k \in W$ and $w^{\prime} \neq k ; r$ is the scenario index having minimum distance with scenario $s$.

3- $\quad P D_{s}(r)=p_{s} * D T_{s}(r) ; s \in W . d$ is chossen such that $P D_{d}=\min P D_{s}$.

4- $\quad W=W-\{d\}, D W=D W+\{d\} ; p_{r}=p_{r}+p_{d}$.

5- Steps 2 to 4 are repeated to meet number of deleted scenarios target.

Fast forward algorithm follows the similar steps, except, the scenario reduction process is repeated recursively until the required number of reduced scenario is selected. If the required number of reduced scenario is very small, such strong reduction process is followed. The work proposed here uses the BR algorithm to get the optimal reduced scenario. The psedu code for BR technique is given in Fig. 1 .

The above algorithms are implemented in MATLAB. The computation time to reduce 1000 scenarios (with 744 dimensions in each scenario) into 10 scenarios is about $4 \mathrm{~min}$. The simulation is performed on a $4 \mathrm{GHz}$ system. Figure 2 shows the scenario tree representing the stochastic pool price. The sum of probabilities over all the scenarios is equal to 1 . To introduce stochasticity in the solution, 10 price scenarios are considered for each time interval $(744 \times 10)$.

\section{Stochastic Portfolio Allocation Problem}

The GenCo is assumed to have contract allocation in multiple locations and behaves as a price taker i.e., its production does not influence electricity market price.

\section{Revenue Involved Contracts}

For $Z(m=1, \ldots, Z)$ zones considered, the GenCos home location is indexed as $1(m=1)$ having: 1$)$ home spot

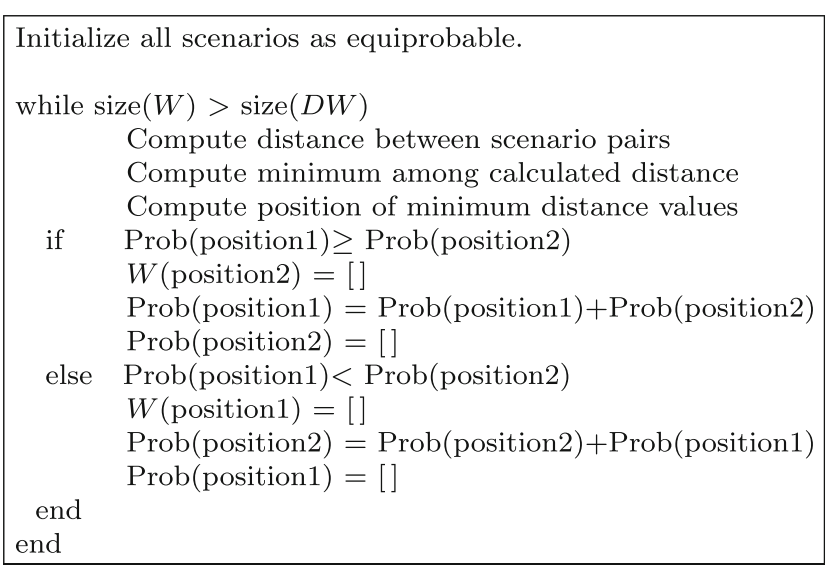

Fig. 1 Pseudo code for BR technique 


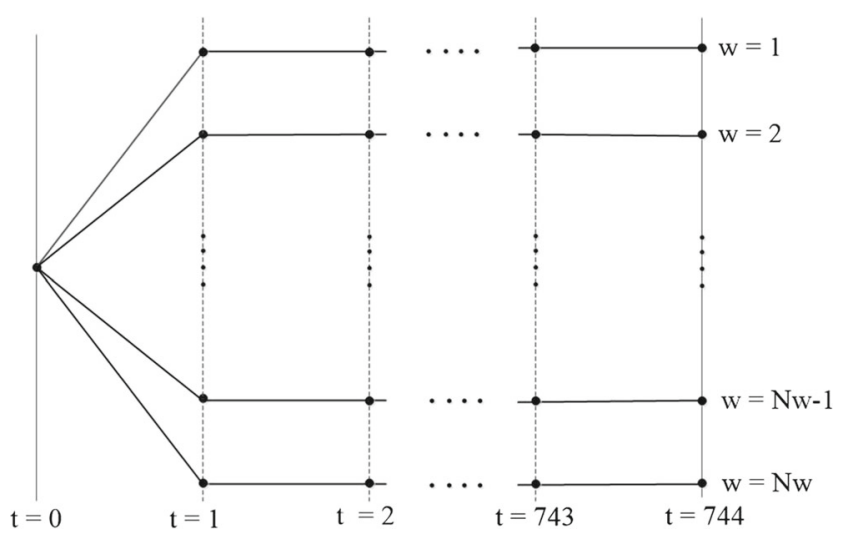

Fig. 2 Price scenario tree

market sharing; 2) home bilateral contract; 3) Forward contract with other zones and 4) corresponding hedging options with other zones. The GenCo faces uncertainties pertaining to spot price of home zone, spot price of inter-zonal transactions and inter-zonal hedging options.

\section{Spot Market}

The revenue obtained by the GenCo in the spot market for each spot price scenario $\left(r_{s}^{w}\right)$ depends on the time period $t$ and given by

$r_{S}^{w}=\sum_{t=1}^{T} \lambda_{s}^{w}(t) e_{s}^{w}(t)$

where, $\lambda_{s}^{w}(t)$ is the spot market trading price of the considered scenarios (Euros/MWh); $e_{s}^{w}(t)$ is the energy contracted in spot market for the corresponding spot price scenarios (MWh).

\section{Forward Contracts}

The most common forward contracts are bilateral contracts used to hedge against spot price risks. For a GenCo it is an agreement between the GenCo and load entity to deliver certain amount of energy for a specified future duration at price $\lambda_{f}$. The revenue obtained can be calculated as

$r_{F}^{m}=\sum_{m=2}^{Z} \sum_{t=1}^{T} \lambda_{f}^{m}(t) e_{f}^{m}$

where, $\lambda_{f}^{m}(t)$ is the effective inter-zonal contract price with consumer of mth zone [Euros/MWh] and $e_{f}^{m}$ is the corresponding energy contracted in inter-zonal forward market [MWh]. Contract involved with other region indexed as $m=2 \ldots Z$. For these contracts the difference in prices of two zones is the applicable congestion charge for the corresponding contract. This is partially or fully supplied by the GenCo, depending on the market rule. The congestion charge is given by,

$$
\text { Congestion Charges }=\lambda_{s}^{m}(t)-\lambda_{s}^{1}(t)
$$

where, $\lambda_{s}^{m}(t)$ is the spot electricity price of mth trading zone [Euros/MWh] and $\lambda_{s}^{1}(t)$ is the spot electricity price of GenCos home zone [MWh]. The contract holder pays the charges for such inter zonal contracts proportionately based on congestion factor $\gamma(0 \leq \gamma \leq 1)$, as per market rule $\gamma$ linearly varies from $0.5-1$. The effective contract prices for GenCo would be

$\lambda_{f}^{m}(t)=\lambda_{B C}^{m}(t)-\gamma\left(\lambda_{s}^{m}(t)-\lambda_{s}^{1}(t)\right)$

where, $\lambda_{B C}^{m}$ is the agreed upon price for the forward contract with consumer of mth zone. For within zone(intra zonal) bilateral contract $(m=1)$, congestion factor $\gamma$ is zero, as the consumer pays the agreed contract price $\left(\lambda_{B C}^{m}\right)$ within the home location. Let the effective contract price be $\lambda_{B}$. The revenue $r_{B}$ is given by,

$r_{B}=\lambda_{B} e_{B}$

\section{Hedging Options}

A key risk in electricity market is the price variation across locations, known as congestion risk. This can be hedged with options/CfDs, depending on their availability at the time of congestion. Options are considered here as hedging instrument, as they do not give a negative payoff. However, the price of option hedging is higher compared to other hedging instruments, as they are associated with a premium. Options as hedging instrument are considered between areas spanning each trading interval. Consequence of a GenCo facing congestion fee in a day-ahead market with options is given in Table 1.

The associated pay-off for the holder of options long position (buying) is given by,

$\begin{cases}\lambda_{s}^{m}(t)-\lambda_{s}^{1}(t), & \lambda_{s}^{m}(t)>\lambda_{s}^{1}(t) \\ 0, & \lambda_{s}^{m}(t)<\lambda_{s}^{1}(t)\end{cases}$

So, the effective contract price of options purchase $\left(\lambda_{h}^{m}\right)$ for inter-zonal transaction would be the difference between the respective zonal price and the option premium $\left(\lambda_{\text {prim }}^{m}\right)$.

$\lambda_{h}^{m}(t)=\lambda_{s}^{m}(t)-\lambda_{\text {prim }}^{m}$

Table 1 GenCo's consequence facing congestion fee

\begin{tabular}{ll}
\hline Events & Payment to GenCo \\
\hline Spot market & $\lambda_{s}^{m} e_{s}^{m}$ \\
Congestion fee & $e_{s}^{m}\left(\lambda_{s}^{m}-\lambda_{s}^{1}\right)$ \\
Option & $e_{s}^{m}\left(\lambda_{s}^{m}-\lambda_{s}^{1}\right)-e_{s}^{m} \lambda_{\text {prim }}^{m}$ \\
Net payment & $\boldsymbol{e}_{s}^{\boldsymbol{m}}\left(\lambda_{s}^{\boldsymbol{m}}-\lambda_{\text {prim }}^{\boldsymbol{m}}\right)$ \\
\hline
\end{tabular}

Note: Significance of Bold - net payment of GenCo in a congested environment 
Because the option exercise is dependent on the system marginal price scenario, the pay-off is also dependent on the considered trading period $t$. The option revenue over the trading period is given as,

$r_{H}^{m}=\sum_{m=2}^{Z} \sum_{t}^{T} \lambda_{h}^{m}(t) \times e_{h}^{m}(t)$

where, $\lambda_{h}^{m}$ is the effective hedging contract price with consumer of mth zone [Euros/MWh] and $e_{h}^{m}$ is the traded energy in hedging contract [MWh]. When spot price at interzonal locations are higher than home location, the GenCo is assumed to pay the congestion fee. However, the GenCo receives a rebate equal to the congestion fee for relieving congestion when inter-zonal price is less than the home zone. In such cases, the holder is said to have a short position in option (selling).

\section{Expected Profit}

A mean variance approach is used for portfolio optimization. As per the Markowitz mean-variance portfolio theory, the average value of profit from forecast price for each trading interval is considered as the expected value $(\operatorname{Exp}(\pi))$ and its variance is considered as risk constraint $(\operatorname{Var}(\pi))$. The analysis considers inter dependency between contracts through a correlation matrix. The profit $\pi_{C}$ for each trading interval is given by

$\pi_{C}=r_{S}^{w}+r_{F}+r_{B}+r_{H}-c\left(P_{G}\right)$

where, $c\left(P_{G}\right)$ is a quadratic cost function of power awarded with coefficients $a, b$ and $c$ as.

$c\left(P_{G}\right)=\left[a\left(P_{G}^{2}\right)+b\left(P_{G}\right)+c\right] u(t)+c^{s u}(t)$

The total cost is the summation of the quadratic function of power awarded and constant start up cost. The start up cost $\left(c^{s u}(t)\right)$ follows the following limiting constraints between consecutive trading intervals.

$c^{s u}(t) \geq c^{s u}(u(t)-u(t-1)), c^{s u}(t) \geq 0$.

The operating constraints of the GenCo include the minimum and maximum power output as,

$P_{\text {gmin }} u(t) \leq P_{G}(t) \leq P_{\text {gmax }} u(t)$

Now, the expected value of profit is given by,

$\operatorname{Exp}(\pi)=\operatorname{Exp}\left[r_{S}+r_{F}+r_{H}+r_{B}-c\left(P_{G}\right)\right]$

Intra-zonal bilateral contracts are known at the time of planning, so its expected value is fixed through out the planning period and can be excluded from the mean calculation. Thus, the expected profit can be re-written as,

$\operatorname{Exp}(\pi)=\operatorname{Exp}\left[r_{S}+r_{F}+r_{H}-c\left(P_{G}\right)\right]+r_{B}$
Now, the expected profit for the total planning period is given by,

$$
\begin{aligned}
\operatorname{Exp}\left(\pi_{w}\right)= & \sum_{t}^{T} \varepsilon\left(\lambda_{s}^{w}(t)\right) e_{s}^{w}(t)+\varepsilon\left(\lambda_{f}^{m}(t)\right) e_{f}^{m}(t) \\
& +\varepsilon\left(\lambda_{s}^{m}(t)\right) e_{s}^{m}(t)+\lambda_{B} e_{B}-c\left(P_{G}\right)
\end{aligned}
$$

All the above constraints are true for each scenario of the spot price.

\section{Risk Model}

The revenue obtained from intra-zonal (home location) bilateral contract has zero variance due to its fixed price and quantity. The uncertainty model involves volatility of spot, inter-zonal contracts and options hedging. The uncertainty of total profit can be evaluated as variance of the profit and is given by Eq. 17 .

$$
\begin{aligned}
\operatorname{Var}(\pi)= & \operatorname{Var}\left[r_{S}+r_{F}^{m}+r_{H}^{m}\right] \\
\operatorname{Var}(\pi)= & \operatorname{Var}\left(r_{S}^{w}\right)+\operatorname{Var}\left(r_{F}^{m}\right)+\operatorname{Var}\left(r_{H}^{m}\right) \\
& +2 \operatorname{Cov}\left(r_{S}^{w}, r_{F}^{m}\right)+2 \operatorname{Cov}\left(r_{S}^{w}, r_{H}^{m}\right) \\
& +2 \operatorname{Cov}\left(r_{F}^{m}, r_{H}^{m}\right)
\end{aligned}
$$

The variance for the total planning horizon is given by,

$$
\begin{aligned}
\operatorname{Var}\left(\pi_{w}\right)= & \sum_{t}^{T} e_{s}^{w}(t)^{2} \sigma\left(\lambda_{s}^{w}(t)\right)+e_{f}^{m}(t)^{2} \sigma\left(\lambda_{f}^{m}(t)\right) \\
& +e_{h}^{m}(t)^{2} \sigma\left(\lambda_{h}^{m}(t)\right)+2 \operatorname{Cov}\left(r_{S}^{w}, r_{F}^{m}\right) \\
& +2 \operatorname{Cov}\left(r_{S}, r_{H}^{m}\right)+2 \operatorname{Cov}\left(r_{F}^{m}, r_{H}^{m}\right)
\end{aligned}
$$

where, $\sigma$ is the variance operator and $\operatorname{Cov}$ is the covariance operator.

Equation 18 shows the profit variance with considered spot price scenarios. The covariance shows the correlation between different market prices at each trading interval. Now, the expected profit and its variance are incorporated in the objective function to maximize the profit and minimize the involved risk. The power portfolio optimization model is mathematically represented as,

$\operatorname{maximize} \Pi=\sum_{W} p_{w} \operatorname{Exp}\left(\pi_{w}\right)-\eta p_{w} \operatorname{Var}\left(\pi_{w}\right)$

subject to Eqs. 10-12, 20-23 and

$P_{G}^{w}(t)=e_{s}^{w}(t)+e_{B}^{w}(t)+e_{f}^{m, w}(t)$

$e_{s}^{w}(t), e_{B}^{w}(t), e_{f}^{m, w}(t) \geq 0$

$e_{f}^{m, w, \min }(t) \leq e_{f}^{m, w}(t) \leq e_{f}^{m, w, \max }(t)$

$e_{B}^{w, \min }(t) \leq e_{B}^{w}(t) \leq e_{B}^{w, \max }(t)$ 
Table 2 Generator technical specifications

\begin{tabular}{lll}
\hline Parameters & Value & Unit \\
\hline $\mathrm{P}_{\text {gmax }}$ & 500 & $\mathrm{MW}$ \\
$\mathrm{P}_{\text {gmin }}$ & 40 & $\mathrm{MW}$ \\
$\mathrm{c}$ & 0.00045 & Euros $/ \mathrm{h}$ \\
$\mathrm{b}$ & 16.9 & Euros $/ \mathrm{MWh}$ \\
$\mathrm{a}$ & 311 & Euros $/ \mathrm{MW}^{2} \mathrm{~h}$ \\
Constant start-up cost & 500 & Euros \\
\hline
\end{tabular}

where, $p_{w}$ is the probability of occurrence of scenario $w$ and $\eta$ is the risk aversion factor. Energy terms in the above constraint equations are subjected to spot price scenarios, thus varies dynamically.

\section{Numerical Results and Analysis}

The GenCo is considered to be a thermal power station located at Oslo (Zone 1/home zone) having forward and hedging contracts with Zone 2 (SE3) and Zone 3 (NO5). Table 2 shows the GenCos technical characteristics. GenCos cost function is considered to be same for the entire period of analysis. The GenCo has options along with inter-zonal forward contracts to hedge the congestion charge. The premium value associated with the hedging contract is kept at 1.25 Euros/MWh.

\section{Data and Parameters}

Spot price forecasting involves different methods. As price forecasting is not the focus of this study, historical information based method is used for spot price estimation. Historical data of similar trading intervals for entire planning period are used to estimate spot prices of corresponding trading intervals.

The study is carried out using past market data of NORDPOOL for the month of July (2009-2013) (http://www. nordpoolspot.com/). To introduce stochastic uncertainty Monte Carlo simulation is carried out to generate 1000 random scenarios of spot prices. With the proposed backward

Table 3 Correlation between contract prices

\begin{tabular}{llrrrr}
\hline Contracts & Spot & Forward & Forward & Option $_{2}$ & Option $_{3}$ \\
\hline Spot & 1.0000 & 0.7878 & 0.0705 & 0.1558 & 0.9857 \\
Forward $_{2}$ & 0.7878 & 1.0000 & -0.0357 & -0.4355 & 0.7992 \\
Forward $_{3}$ & 0.0705 & -0.0357 & 1.0000 & 0.0959 & -0.0708 \\
Option $_{2}$ & 0.1558 & -0.4355 & 0.0959 & 1.0000 & 0.1292 \\
Option $_{3}$ & 0.9857 & 0.7992 & -0.0708 & 0.1292 & 1.0000 \\
\hline
\end{tabular}


Fig. 3 Profit standard deviation vs expected profit

reduction technique (BR) 1000 scenarios are reduced to 10 scenarios. For each reduced spot price scenarios, with 6 available contracts, except home bilateral contract, variance co-variance matrices are calculated using MATLAB function. For the presented study 744 trading intervals are considered. With five risky contracts, 744 matrices of size $10 \times 5 \times 5$ are computed. Table 3 shows the average correlation matrix computed for the considered planning period. The primary concern in a mean variance formulation is the right choice of producers risk aversion factor $(\eta)$, which is a private information of the GenCo. Normally risk aversion factor value varies from 0 to 1 . If $\eta=0$, GenCo is risk neutral; if $\eta>0$, GenCo is risk averse; and if $\eta<0$, GenCo is risk loving (rare in electricity market). For this study the range of risk aversion factor $(0-0.00002)$ at random steps are considered.

Table 4 Contract price combinations

\begin{tabular}{lllll}
\hline Subplots & Sets & $\mathrm{A}_{1}($ Euros/MWh $)$ & $\mathrm{A}_{2}$ (Euros/MWh) & Line type \\
\hline SP1/SP3 & Set I & 35.5 & 40 & Plain \\
& Set II & 35.5 & 42 & Dashed \\
& Set III & 35.5 & 44 & Dotted \\
SP2/SP4 & Set I' & 35.5 & 40 & Plain \\
& Set II' $^{\prime}$ & 38 & 42 & Dashed \\
& Set III' $^{\prime}$ & 40 & 44 & Dotted \\
\hline
\end{tabular}


Fig. 4 Profit risk profile with different zonal bilateral price
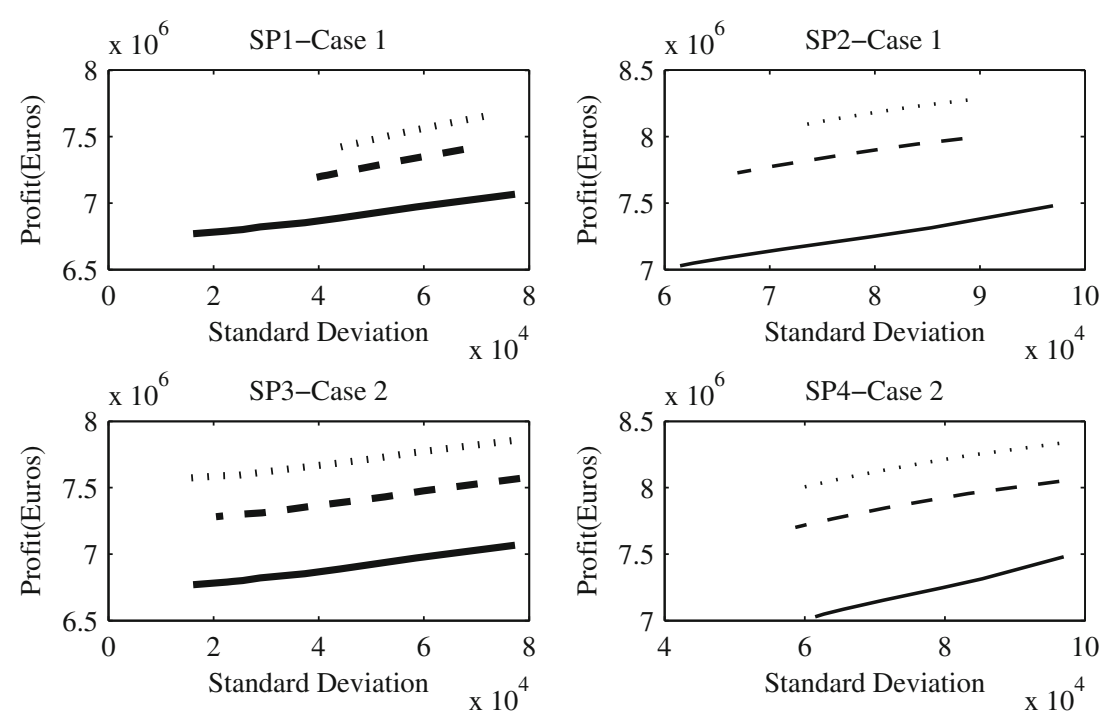

\section{Test Results}

Profit function (19) subject to constraints (10)-(12) and (20)-(23) is optimized to manage portfolio of all involved contracts. For each value risk aversion factor a particular trading strategy is obtained to maximize the portfolio. The MINLP optimization problem have been solved using SBB CONOPT solver of GAMS (https://www.gams.com/) in a core $i 5,3.2-\mathrm{GHz}$ processor and 4-GB RAM computer, with an average solution time of $1.18 \mathrm{~min}$. SBB offers node selection using standard Branch and Bound algorithm and solution is used by NLP algorithm of CONOPT in loop to optimize the NLP problem. SBB finds the best estimate to provide the starting point for NLP models.

\section{Profit Risk Trade-Off}

Equation 18 represents the relationship between contracts through correlation of contract prices. Objective function



Fig. 5 Profit distribution profile
$\Pi$ is maximized for optimal allocation in involved contracts. Optimal portfolio of GenCo is obtained and plotted as efficient frontier for different values of risk aversion factor in Fig. 3. All the portfolio points with mean and variance form a frontier. Portfolios which provide best risk return combination, are called optimal portfolios. The plot concerning these optimal portfolios is known as efficient frontier(EF). The EF plot shows maximum profit at higher risk with corresponding decrease in profile of lower risk.
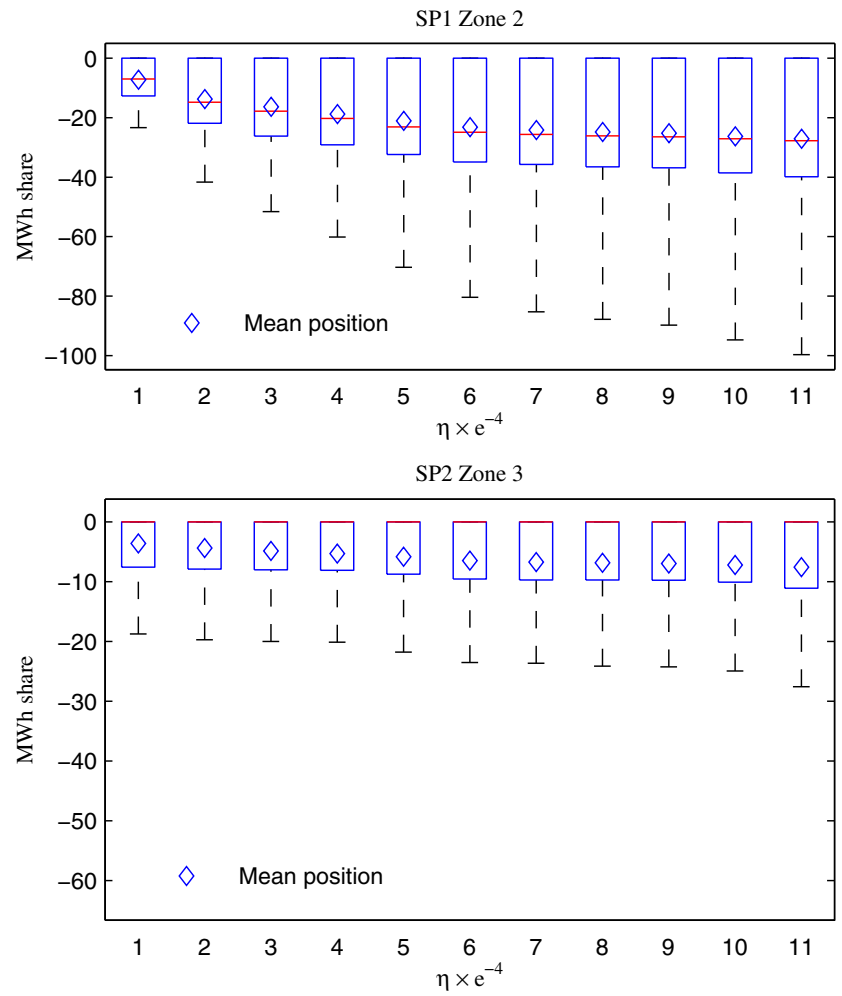

Fig. 6 Long position in options 


\section{SP1 Zone 2}

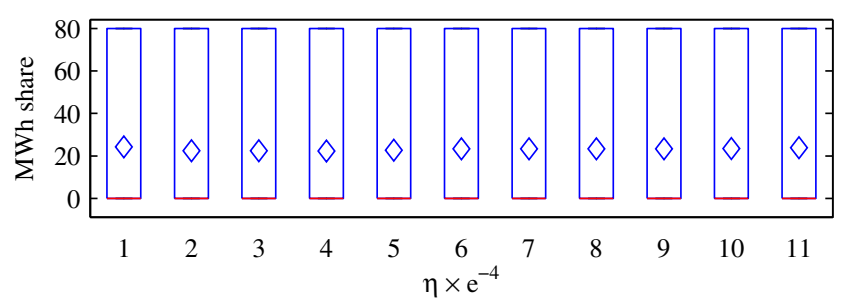

SP2 Zone 3

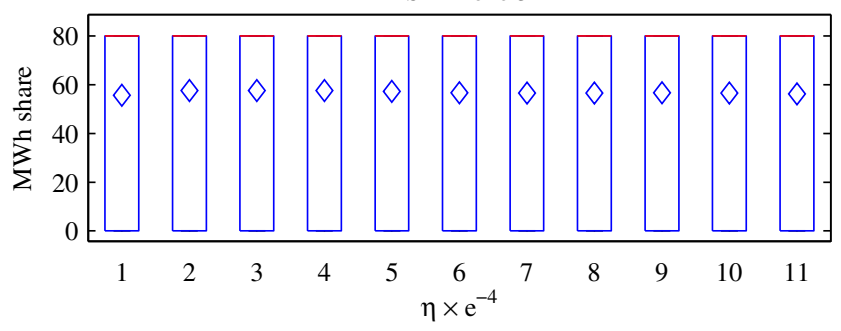

Fig. 7 Short positions in options

Two cases are considered for this study, Case 1: portfolio optimization with hedging instrument and Case 2: portfolio optimization without hedging instruments. EF for the corresponding profit risk trade-off is plotted in Fig. 3. The frontier with hedging instruments (Case 1) shows better profit-risk profile than Case 2, whereas Case 2 has higher value of profit profile with larger risk exposure. The risk averse GenCo will always find Case 1 as a better trading strategy over Case 2 even with lower profit.

\section{Impact of Bilateral Contracts}

Three sets of bilateral contract prices are considered to show the impact of inter-zonal forward contract price on GenCos profit-risk trade-off strategy. Simulation is performed and EFs are plotted in Fig. 4. Subplot1 (SP1), SP2 correspond to Case 1 and SP3, SP4 correspond to the respective
Case 2. Let $A_{1}$ and $A_{2}$ denote the bilateral contract prices (Euros/MWh) of Zone 1 and Zone 2 respectively. Various combination of contract prices considered are listed in Table 4. Last column of the table indicates line type pictured in Fig. 4. For Case 1 (SP1 and SP2), as the bilateral contract price increases, the profit profile has an upward shift with decreasing risk. For Case 2 (SP3 and SP4), the upward shift of the profit profile is more but with higher risk. This implies, without hedging instrument the GenCo may gain more profit but with a higher risk exposure. This further indicates that the parallel shifting of frontiers may not necessarily help in reducing the profit risk, where as the inclusion of options hedging offers overall risk protection.

SP2-Case 1 and SP4-Case 2 which consider increase in forward contract price in both the zones, have equal upward shifting of the EFs. Again Case 1 plot shows better profit risk trade-off strategy compared to Case 2.

\section{Scenarios Risk Trade Off}

Multiple spot price scenarios are generated with random probability through the scenario generation method described in "Problem Formulation". Profit distribution for each random scenario is calculated using the proposed optimization problem for different values of $\eta$. The profits distribution in the risk neutral case $(\eta=0)$ and a risk averse case $(\eta=0.00002)$ are shown Fig. 5. The concentrated profit profile for the risk averse case indicates reduced risk exposure. On the other hand the distributed profit profile for the risk neutral case indicates increased risk exposure.

\section{Optimal Hedging Position of Contracts}

The GenCo participates in buying two option contracts for two zones (Zone $2 \&$ Zone 3 ) to hedge the congestion risk.
Fig. 8 Optimal hedging position of Spot contract quantity

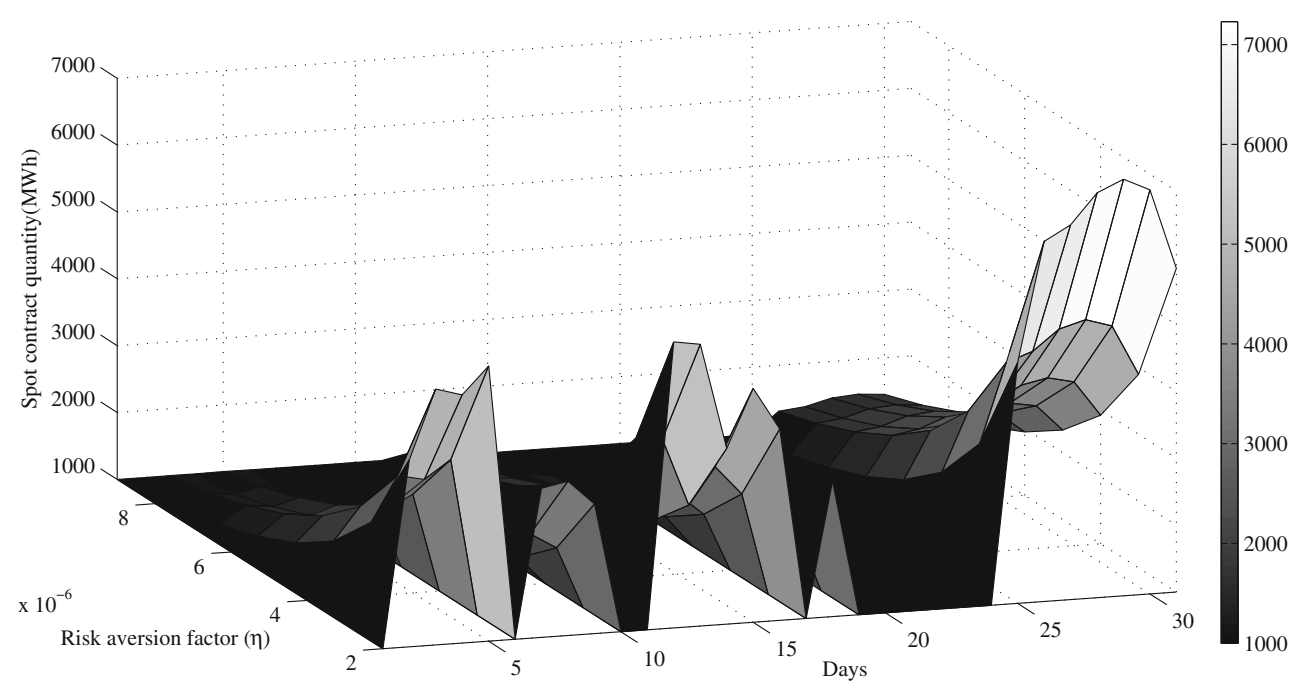


Fig. 9 Percentage contract share for the whole planning period
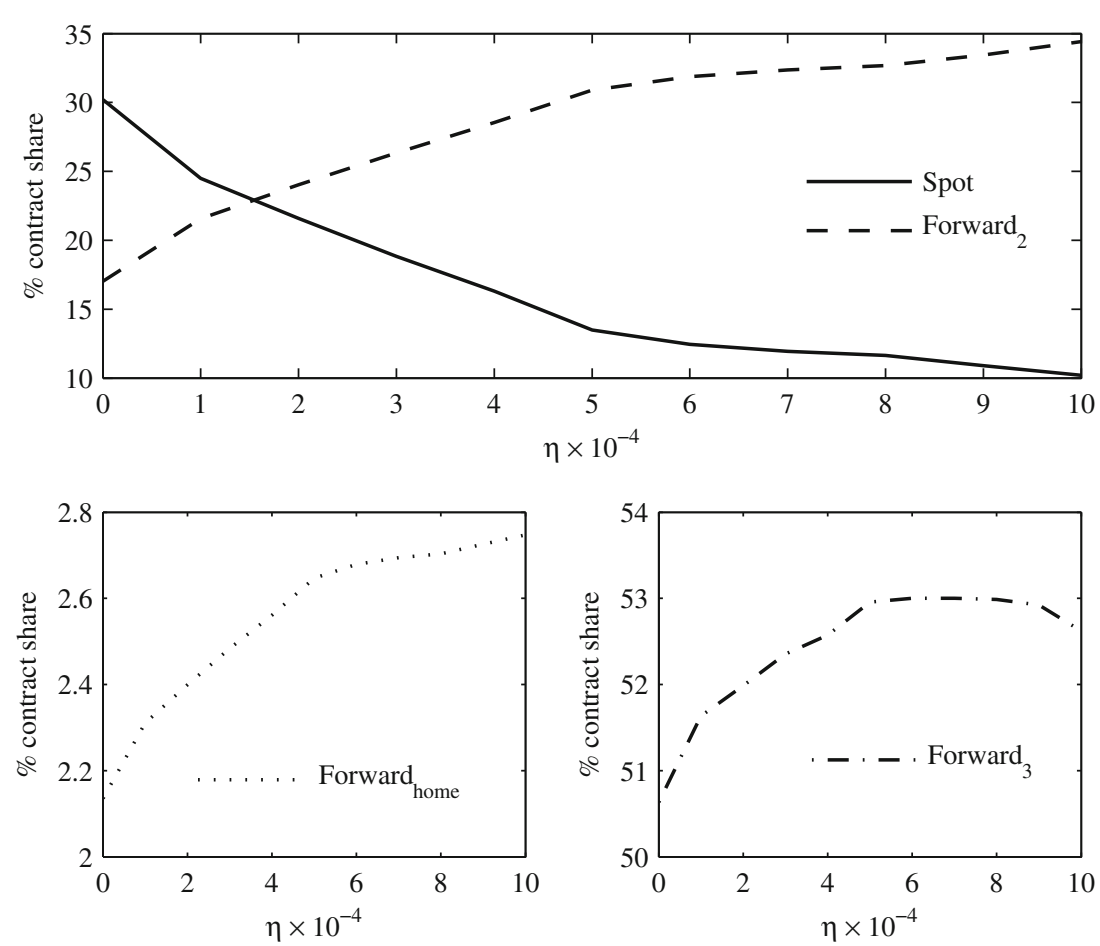

Optimal allocation in forward, spot and options depends on contract prices during the considered trading interval and the involved uncertainties.

Box plot in Fig. 6 shows the distribution of hedging options for the entire planning period. The positive values imply selling of hedging contracts (short position) while negative values imply buying of hedging contracts (long positions). More option instruments are needed to hedge the congestion risk with increasing $\eta$. Figure 6 represents the expected long position of hedging options in a risk environment. As can be seen from SP1 Fig. 6, the mean position of the outcomes tend to occur closer to the median value (horizontal red lines). This implies risk averse behavior of the GenCo and it tends to bid more in options to hedge the congestion with increasing risk aversion factor. In SP2 the median value is higher than the mean position. This makes the GenCo more tolerant to risk. The higher value of inter zonal bilateral price of Zone 3 compared to Zone 2, makes the GenCo bid more in Zone 3 to gain more profit irrespective of the congestion risk. This reflects higher upside potential for the GenCo to bid in Zone 3.

Short positions are plotted in Fig. 7. The red lines in the box plot represent the median position of the distribution. SP1-zone2 with mean $>$ median shows risk averse behavior of the GenCo with less short positions in Zone 2. On the other hand, SP2-zone3 with mean $<$ median shows risk neutral behavior of the GenCo with more short positions in Zone 3. This can also be inferred from Table 3, which shows a strong correlation between Spot and Option 3 in comparison with the weak correlation between Spot and Option 2 . Thus a risk neutral GenCo may find SP2 a more attractive trading strategy and reflects higher upside potential for the GenCo to bid in Zone 3.

Figure 8 shows the variation in spot market allocation for different risk aversion levels and for each trading interval. The average of the trading quantity over each day $(24 \mathrm{~h})$ is considered for the plot. For the initial trading period, spot market allocation is lower due to low market price, while later the spot allocation has an increasing profile. Overall trading allocation decreases with increase in risk aversion factor.

Percentage share of considered physical contracts for the planning period are plotted in Fig. 9. With spot price uncertainty GenCo will trade more in bilateral contract for better risk management. Further with higher value of bilateral contract price of Zone 3 and lower value of congestion charges GenCo will trade more in Zone 3.

\section{Conclusion}

NORDPOOL exercises power options as a financial hedging instrument through Nasdaq, thus making it Europes' largest derivative exchange. The work here demonstrates power options as a hedging tool for inter zonal power transaction. The paper presents a mean variance profit maximization model for GenCo in a multi-zonal market. The 
allocation model is based on NORDPOOL market with spot and forward contracts. To introduce stochasticity in the spot prices, a scenario generation methodology is presented.

Hedging analysis is performed with two inter-zonal spot markets. The results indicate that a strong correlation between Spot and Option 3 (0.9857) (shown in Table 3) compared to correlation between Spot and Option 2 (0.1558), leads to higher allocation of options in Zone 3 and may help in hedging the associated congestion risk with inter-zonal contracts. A comparative analysis using different bilateral prices is shown. The results justify that the inclusion of options provides better risk protection with increasing bilateral contract price. The paper also demonstrates GenCos portfolio selection preferences with and without congestion uncertainty. A congestion relieving situation is demonstrated for an inter-zonal contract involving zonal spot price less than the GenCos home zone price. The plotted results indicates GenCos willingness to bid more in congestion relieved area. The presented study also shows GenCos behavior under risk through probability plot. Risk averse GenCo will have a concentrated profit profile than a risk neutral one. Thus portfolio optimization study with risk management is essential for a GenCo while trading in multiple electricity markets.

It is expected that profit will be higher if congestion are hedged by purchasing FTRs than options. This is because of higher value of options price compared to FTRs. So, further study with FTR allocation along with pool market can be done.

Acknowledgment The authors would like to thank NORD POOL for providing access to electricity prices.

\section{References}

1. Bjorgan R, Liu C, Lawarree J (1999) Financial risk management in a competitive electricity market. IEEE Trans Power Syst 14(4):1285-1291

2. Xu J, Luh PB, White FB et al (2006) Power portfolio optimization in deregulated electricity markets with risk management. IEEE Trans Power Syst 21(4):1653-1659

3. Liu M, Wu FF (2006) Managing price risk in a multimarket environment. IEEE Trans Power Syst 18(2):1512-1519

4. Deng SJ, Oren SS (2006) Electricity derivatives and risk management. Energy 31(6):940-953

5. Eydeland A, Wolyniec K (2003) Energy and power risk management: new developments in modeling, pricing and hedging. Wiley, New Jersey

6. Byström HNE (2003) The hedging performance of electricity futures on the Nordic power exchange. Appl Econ 35:1-11

7. Kaye R, Outhred H, Bannister C (1990) Forward contracts for the operation of an electricity industry. IEEE Trans Power Syst $5(1): 46-52$

8. Niu H, Baldick R, Zhu G (2005) Supply function equilibrium bidding strategies with fixed forward contracts. IEEE Trans Power Syst 20(4):1859-1867
9. Tanlapco E, Lawarrée J, Liu C (2002) Hedging with futures contracts in a deregulated electricity industry. IEEE Trans Power Syst 17(3):577-582

10. Marckhoff J, Wimschulte J (2009) Locational price spreads and the pricing of contracts for difference: evidence from the Nordic market. Energy Econ 31(2):257-268

11. Paravan D, Sheblé G, Golob R (2004) Price and volume risk management for power producers. In: Proceedings of the 8th international conference on probabilistic methods applied to power systems. Ames, Iowa, September 2004, pp 699-704

12. Sen S, Yu L, Genc T (2006) A stochastic programming approach to power portfolio optimization. Oper Res 54(1):55-72

13. Ghosh K, Ramesh VC (1997) An option model for electric power markets. Int J Electric Power 19(2):75-85

14. Brooks R, El-keib AA (1998) A life-cycle view of electricity future contracts. J Energy Fin Develop 3(2):171-183

15. Gedra TW (1994) Optional forward contracts for electric power markets. IEEE Trans Power Syst 9(4):1766-1773

16. Chen X, He Y, Song YH et al (2004) Study of impacts of physical contracts and financial contracts on bidding strategies of GENCOs. Int J Elect Power Energy Syst 26(9):715-723

17. Collins RA (2002) The economics of electricity hedging and a proposed modification for the futures contract for electricity. IEEE Trans Power Syst 17(1):100-107

18. Chung TS, Zhang SH, Yu CW et al (2003) Electricity market risk management using forward contracts with bilateral options. IEE Proc Gener Transm Distrib 150(5):588-594

19. Azevedo F, Vale ZA, Oliveira PBM (2007) A decision support system based on particle swarm optimization for multiperiod hedging in electricity markets. IEEE Trans Power Syst 22(3):995-1003

20. Conejo AJ, Bertrand RG, Carrión M et al (2008) Optimal involvement in futures markets of a power producer. IEEE Trans Power Syst 23(2):703-711

21. Pineda S, Conejo AJ (2012) Managing the financial risks of electricity producers using options. Energy Econ 34(6):22162227

22. Pineda S, Conejo AJ (2013) Using electricity options to hedge against financial risks of power producers. J Mod Power Syst Clean Energy 1(2):101-109

23. Guan X, Wu J, Gao F et al (2008) Optimization based generation assest allocation for forward and spot markets. IEEE Trans Power Syst 23(4):1796-1808

24. Fanelli V, Maddalena L, Musti S (2016) Asian options pricing in the day-ahead electricity market. Sustain Cities Soc 27:196-202

25. Liu YF, Wu FF (2007) Risk management of generators' strategic bidding in dynamic oligopolistic electricity market using optimal control. IET Gener Transm Distrib 1(3):388-398

26. Ansari B, Kian AR (2015) A dynamic risk-constrained bidding strategy for generation companies based on linear supply function model. IEEE Syst J 9(4):1463-1474

27. Tanlapco E, Lawarree J, Liu CC (2002) Hedging with futures contracts in a deregulated electricity industry. IEEE Trans Power Syst 17(3):577-582

28. Li T, Shahidehpour M (2005) Risk-constrained FTR bidding strategy in transmission markets. IEEE Trans Power Syst 20(2):10141021

29. Maenhoudt M, Deconinck G (2014) Strategic offering to maximize dayahead profit by hedging against an infeasible market clearing result. IEEE Trans Power Syst 29(2):854-862

30. Rockafellar RT, Wets RJB (1991) Scenarios and policy aggregation in optimization under uncertainty. Math Oper Res 16(1):119147

31. Dupacová J, Kuska NG, Römisch W (2003) Scenario reduction in stochastic programming: an approach using probability metrics. Math Program A 95:493-511 
Debasmita Panda received M.Tech in Energy Systems from Indian Institute of Technology Bombay, Mumbai. Currently, she is pursuing $\mathrm{Ph} . \mathrm{D}$. from the Department of Electrical Engineering, Indian Institute of Technology Kanpur. Her research interest includes electricity market risk analysis, portfolio management in deregulated electricity market.
S. N. Singh received the M. Tech and Ph.D. degrees from the Indian Institute of Technology Kanpur, in 1989 and 1995, respectively. He is currently a Professor in the Department of Electrical Engineering, Indian Institute of Technology Kanpur. His research interests include power system restructuring, FACTS, power system optimization \& control, planning, distributed generation, wind power, etc. Prof. Singh is a Fellow of INAE (India) and Fellow of IE (India) and IETE (India), IET (U.K.) and Fellow of the IEEE. 